\title{
Novel Synthesis of Unsaturated Pigment Anthracene Triazole Acrylate via Click Chemistry to Prepare Colored Binder for Textile Printing
}

\author{
K. Haggag ${ }^{1}$, N.S. Elshemy ${ }^{1}$, A.I. Hashem ${ }^{2}$, Z.M. Mahmoud ${ }^{1}$ and F.A. Kantouch ${ }^{1}$ \\ ${ }^{1}$ Textile Research Division, National Research Centre, Cairo, Egypt. \\ ${ }^{2}$ Chemistry Department, Faculty of Science, Ain Shams University, Cairo, Egypt.
}

\begin{abstract}
T HIS WORK represents the synthesis and preparation of new unsaturated pigment, 2-anthracene triazole acrylate, via click reaction. The prepared pigment was used as a colored binder for textile printing with different fabrics types. Optimum of the prepared pigment content in the printing paste and its effect on the fastnesses properties of the prints were evaluated. This pigment contains unsaturated groups that could be co-polymerized with monomers to produce colored binders. The Measurements and Characterization of the prepared pigment (2-anthracene triazole acrylate) as particle size, particle size distribution, Glass transition temperature $(\mathrm{Tg})$, Stiffness properties as well as its rheological properties to evaluate if this prepared pigment can be used as a colored binder in textile printing of different fabrics. The prepared pigment (2-anthracene triazole acrylate) was considered as a monomer and copolymerized with acrylic acid and butyl acrylate and characterized. From the obtained data it can be concluded that this pigments would be a part from binder chains which enhances rubbing and fastness properties of the prints fabrics.
\end{abstract}

Keywords: Emulsion polymerization, Co-polymer, Colored binder, Pigment, Textile printing, Click chemistry.

\section{Introduction}

Click Chemistry is a term that was introduced by Karl Barry Sharpless in 2001 to describe reactions that are wide in scope, high yielding, has little side products, simple reaction and purification conditions[1,2]. The copper (I) catalyzed cycloaddition of azides and alkynes (CuAAC) developed by Professors Fokin-Sharpless [3] has become good example of click reaction. Huisgen, R. was the first to understand the scope of 1,3-dipolar cycloaddition reaction which has been widely used in organic synthesis [4]. The traditional azide alkyne Huisgen cycloaddition reaction joins an organic azide and alkyne together by heating, often to more than $100{ }^{\circ} \mathrm{C}$ for least several hours that produces a mixture of 1,4- and 1,5- disubstituted triazoles. Copper catalysts discovered by Fokin and Sharpless accelerate the reaction to minutes and at much lower temperatures. The result of this copper catalyzed reaction is mostly a 1, 4-disubstituded triazole product.

Colored binders are obtained by emulsion copolymerization of pigment particles and monomers, so that the pigment molecules will be chemically bonded with binders. This technique could improve the fastness properties of the pigments [5]. This work describes a new method of printing fabrics with pigment. The prepared pigment (2-anthracene triazole acrylate) was considered as a monomer and copolymerized with acrylic acid and butyl acrylate. Therefore the pigments would be a part from binder chains which enhances rubbing and fastness properties of the prints.

Emulsion polymerization is a versatile technique, generally utilized in industry to produce latexes for an extensive change of utilization including paints, coatings, adhesives, and binders in the textiles and paper industries [6,7]. The predominant parts of an emulsion polymerization recipe are the monomer(s), dispersing medium (usually water), surfactant and initiator. Emulsion polymerization includes the emulsification of monomers in an aqueous phase, and stabilization of the droplets by a surfactant [8-10].

With the public's mature demand in recent times pressurized the textile industry for use of natural colorants, without any harmful effects on environment and aquatic ecosystem, and with more developed functionalities simultaneously,

*Corresponding author e-mail: n.s.elshemy@nrc.sci.eg

DOI: 10.21608/EJCHEM.2018.4057.1356

(C)2017 National Information and Documentation Center (NIDOC) 
new technique which saves time and energy and enhancement the final properties of the textile that consumer use. Advanced developments for the saving energy resources and their sustainable use for multifunctional clothing are gaining pace now [11-14].

The present study highlights on the preparation of new pigment, 2-anthracene triazole acrylate, via click reaction. The prepared pigment (2-anthracene triazole acrylate) was considered as a monomer and copolymerized with acrylic acid and butyl acrylate. Therefore the pigments would be a part from binder chains which enhances the textile printability as well as rubbing and all over the fastness properties of the prints. The prepared pigment was tested with different fabrics types to optimum pigment content in the printing paste This pigment contains unsaturated groups that could be co-polymerized with monomers to produce colored binders.

\section{Experimental}

\section{Chemicals:}

The chemicals used in this study include Butyl acrylate (BA, 99\%, MW $128.17 \mathrm{~g} / \mathrm{mol}$, Merck Schuchardt OHG), Acrylic acid (AAc, 99.5\%, MW 72.06 g/mol, Panreac Sintesis),<smiles>Nc1ccc2cc3ccccc3cc2c1</smiles>

2-aminoanthracene
$+\mathrm{NaN}_{3}$

sodium azide nitrite: (NaNO2, 98\%, MW 69 g/mol, Merck Schuchardt OHG), 2-aminoanthracene: (C14H11N, 90\%, MW 193.24 g/mol, Sigma-Aldrich Chemie $\mathrm{GmbH})$, Propargyl acrylate: (98\%, MW $110.11 \mathrm{~g} /$ mol, Sigma-Aldrich Chemie $\mathrm{GmbH}$ ). Copper (II) Sulfate: (CuSO4, 99.9\%, MW 159.61 g/mol, Merck Schuchardt OHG), Sodium Ascorbate: (NaAsc, 99.9\%, MW $198.11 \mathrm{~g} / \mathrm{mol}$, Merck Schuchardt OHG) and Tris((1-benzyl)-H- 1,2,3-triazole-4-yl)methyl) amine: (TBTA, 97\%, MW 530.63 g/mol, SigmaAldrich Chemie $\mathrm{GmbH}$ ).

Printing auxiliaries: Thickener: (Alcoprint PTP; synthetic thickener based on polyacrylic acid) was supplied by Ciba Specialty Chemicals Inc.

\section{Preparation:}

\section{Preparation of 2-azidoanthracene}

A solution of sodium nitrite $(0.5 \mathrm{~g} \mathrm{NaNO}$ $/ 16 \mathrm{ml}$ water) was added dropwise to a solution of 2-aminoanthracene $(1 \mathrm{~g} / 30 \mathrm{ml}$ water $)$ and $3 \mathrm{ml}$ concentrated sulfuric acid at $0^{\circ} \mathrm{C}$ over 5 minutes. The reaction mixture was stirred at $0^{\circ} \mathrm{C}$ for 30 minutes, then a solution of sodium azide (0.6 g $/ 5 \mathrm{ml}$ water) was added dropwise over 10 minutes. The solution was slowly warmed to room temperature and kept stirring for $5 \mathrm{~h}$. The precipitate was isolated by filtration (Scheme1).<smiles>[N-]=[N+]=Nc1ccc2cc3ccccc3cc2c1</smiles>

2-azidoanthracene

Scheme 1. Preparation of 2-azidoanthracene.

Sodium dodecyl sulphate (SDS, 97\%, MW $288.38 \mathrm{~g} / \mathrm{mol}$, Merck Schuchardt $\mathrm{OHG}$, as the emulsifier), potassium persulphate/glucose as a redox initiator, (KPS, 98\%, MW $270.33 \mathrm{~g} / \mathrm{mol}$, Merck Schuchardt OHG) and Glucose (95\%, MW 198.17, RFCL Limited). Deionised water was used in all experiments. The monomers were distilled to remove inhibitors before use. All other chemicals were used as received.

Chemicals used in preparation of anthracene triazole acrylate pigment include Sodium

\section{Preparation of 2-anthracene triazole acrylate pigment}

2-azidoanthracene $0.5 \mathrm{~g}$ and $0.3 \mathrm{~g}$ propargyl acrylate were placed in a $250 \mathrm{ml}$ round bottom flask charged with 3:1 mixture (v/v) of DMF and water $(60 \mathrm{ml}) .0 .1 \mathrm{~g}$ Copper (II) Sulfate, $0.2 \mathrm{~g}$ sodium ascorbate and $0.1 \mathrm{~g}$ TBTA were added at room temperature. The reaction mixture was stirred for $8 \mathrm{hrs}$ at room temperature. After removing the volatile solvents, the residue was treated with methanol $(10 \mathrm{ml})$ and then the insoluble solid was filtered of (Scheme 2) [15].

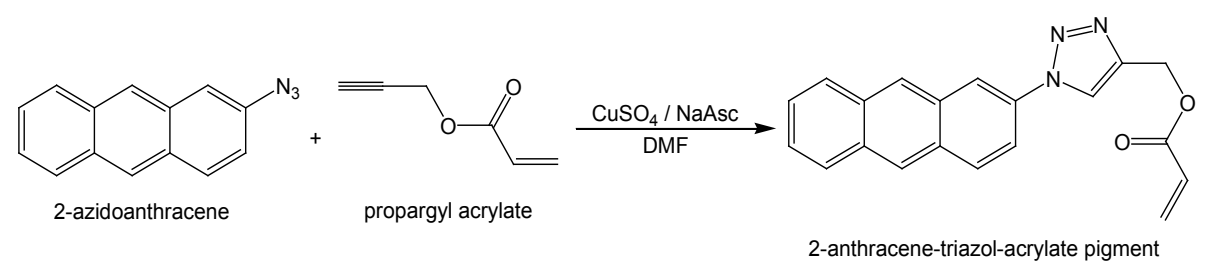

Scheme 2. Preparation of 2-anthracene triazole acrylate pigment. 
Preparation of colored binder (micro-emulsion copolymerization of 2-anthracene triazole acrylate - butyl acrylate - acrylic acid)

The micro-emulsion co-polymerization process was carried out using mixture of BA, AAc and 2-anthracene triazole acrylate comprising 10/10/17 wt. \% AAc / BA / pigment. A typical polymerization procedure was carried out in a 4-necked flask equipped with a reflux condenser, a thermometer, an addition funnel, a mechanical stirrer and $\mathrm{N}_{2}$ gas inlet and outlet.

A solution of $2 \mathrm{~g}$ wt. $\%$ BA, $5 \mathrm{~g}$ wt. $\%$ SDS, $0.2 \mathrm{~g}$ wt. $\%$ of KPS, $0.1 \mathrm{~g}$ wt. $\%$ glucose and 57.7 $\mathrm{ml}$ water were charged to the reactor to prepare the pre-microemulsion. $\mathrm{N}_{2}$ gas was bubbled through the microemulsion for 10 minutes. The flask was then heated to $70^{\circ} \mathrm{C}$ with mild stirring (200 rpm) for 20 minutes. Then the monomers in the addition funnel were continuously and slowly added to the polymerizing micro-emulsion through $2 \mathrm{hrs}$ with mild stirring (200 rpm).

\section{Printing \\ Preparation of printing pastes}

The printing pastes were prepared according to the formulation given in Table 1. Ammonia, urea, diammonium phosphate and binder were mixed with water. The synthetic thickener PTP was then introduced and the paste was stirred using a high shear mixer for 10 minutes to allow full viscosity to develop. The pigment was then added to the mixture with stirring using a high shear mixer for 15 minutes. If the viscosity of the printing pastes decreases, a slight amount of the thickener is added to maintain consistent viscosity values of the pastes at $21,000 \mathrm{cps}$ at rate of shear of $2.180[16,17]$.

TABLE 1. Formulation of the printing paste.

\begin{tabular}{|c|c|}
\hline Components & Weight (in grams) \\
\hline Water & $\mathrm{X}$ \\
\hline Ammonia (25 \%) & 0.5 \\
\hline Binder & $15-20$ \\
\hline Thickener (Alcoprint PTP) & 2 \\
\hline Diammonium phosphate & 0.5 \\
\hline Urea & 4 \\
\hline Pigment & $3-5$ \\
\hline Total & $100 \mathrm{~g}$ \\
\hline
\end{tabular}

\section{Printing technique}

All the printing pastes were applied to the fabrics using the flat screen printing technique.

\section{Print fixation}

Print fixation was done by thermofixation at $160^{\circ} \mathrm{C}$ for 4 minutes in an automatic thermostatic oven (Wemer Mathis Co., Switzerland). Thermofixation also was done at different periods and temperature to determine the optimum condition of fixation.

\section{Measurements and Characterization}

Particle size and particle size distribution

Particle sizes of the polymerized microemulsion latexes were determined using a JEOLGEM transmission electron microscope and particle size distribution was determined using Leica Qwin 500 image analyzer.

\section{Glass transition temperature ( $T g$ )}

The Tg of the prepared binders were measured by differential scanning calorimetry (DSC) Shimadzu- 50

\section{UV/Visible spectra}

The ultraviolet-visible absorbance spectrum of the prepared pigment was measured using the Shimadzu UV/V spectrophotometer.

\section{Color strength measurements}

The color strength of the printed samples expressed as K/S was evaluated by high reflectance technique [18]. Reflectance measurements of the printed fabrics were performed on Perkin - Elmer Lambda 3B, UV/V Spectrophotometer. The color strength expressed as K/S was assessed by applying the Kobelka Munk equation as follows:

$$
\mathrm{K} / \mathrm{S}=(1-\mathrm{R})^{2} / 2 \mathrm{R}-\left(1-\mathrm{R}_{0}\right)^{2} / 2 \mathrm{R}_{\mathrm{O}}
$$

Where:

$\mathrm{R}, \mathrm{R}_{\mathrm{O}}$ are decimal fractions of the reflectance of the printed and unprinted fabric respectively 
$\mathrm{K}=$ absorption coefficient.

$\mathrm{S}=$ scattering coefficient.

Fastness properties

The colorfastness to rubbing (dry and wet) [19], to washing [20], to perspiration (alkaline, acidic) [21].

\section{Color fastness to light}

Color fastness to light was determined according to AATCC test method (16A- 1989). The evaluation was established using the blue scale as reference of color change [22].

\section{Stiffness properties}

Stiffness of printed and unprinted samples was determined according to ASTM test method D 1388 - 96 using the cantilever apparatus [23].

Rheological properties of the printing pastes

The rheological properties of the pastes were measured using a rotary viscometer (Rheomat 15, Zurich, Switzerland).

\section{Results and Discussion}

Effect of pigment concentration in the printing paste on properties of the prints

Table 2 shows the effect of pigment content in the printing paste on the color strength and fastness properties of the printed cotton samples, using BA-AAc commercial binder. It is evident that the color strength of the prints increases with increasing the pigment content. All prints have very good fastness to light rubbing, washing, and perspiration while the stiffness of the printed samples increases slightly with the increasing the pigment content. From the results, we can conclude that the optimum pigment content in the printing paste is $4 \%$.

\section{UV/Visible spectrum}

The prepared 2- anthracene triazole acrylate pigment is typically yellow in color. The electronic spectrum of dilute solution of it in DMSO is shown in Figure 1. The pigment shows an absorption band in the visible region at $\lambda_{\text {max }}=445 \mathrm{~nm}$.

Effect of monomers content ratio on the properties of micro emulsion binder

Various micro-emulsion binders were prepared by different monomers composition using, $10 / 10 / 13,10 / 10 / 17$ or $10 / 10 / 20$ wt. $\%$ AAc/ $\mathrm{BA} /$ pigment wt $\%$. Table 14 shows the effect of monomers content ratio on the properties of microemulsion polymer. The results indicate that

TABLE 2. Effect of pigment content in the printing paste on properties of the prints.

\begin{tabular}{|c|c|c|c|c|c|c|c|c|c|c|c|}
\hline \multirow{3}{*}{$\begin{array}{l}\text { Pigment } \\
\text { conc. (\%) }\end{array}$} & \multirow{3}{*}{$\mathbf{K} / \mathbf{S}$} & \multirow{3}{*}{ Light } & \multirow{3}{*}{ Stiffness } & \multirow{2}{*}{\multicolumn{2}{|c|}{ Rubbing }} & \multirow{2}{*}{\multicolumn{2}{|c|}{ Washing }} & \multicolumn{4}{|c|}{ Perspiration } \\
\hline & & & & & & & & \multicolumn{2}{|c|}{ Acidic } & \multicolumn{2}{|c|}{ Alkaline } \\
\hline & & & & Dry & Wet & Alt & Stain & Alt & Stain & Alt & Stain \\
\hline 2 & 2.7 & 6 & 1420 & $3-4$ & 3 & $4-5$ & $4-5$ & $4-5$ & $4-5$ & $4-5$ & $4-5$ \\
\hline 3 & 3.8 & $6-7$ & 1450 & $3-4$ & 3 & $4-5$ & $4-5$ & $4-5$ & $4-5$ & $4-5$ & $4-5$ \\
\hline 4 & 4.3 & 7 & 1490 & $3-4$ & 3 & $4-5$ & $4-5$ & $4-5$ & $4-5$ & $4-5$ & $4-5$ \\
\hline 5 & 4.4 & 7 & 1530 & 3 & $2-3$ & $4-5$ & $4-5$ & $4-5$ & $4-5$ & $4-5$ & $4-5$ \\
\hline
\end{tabular}

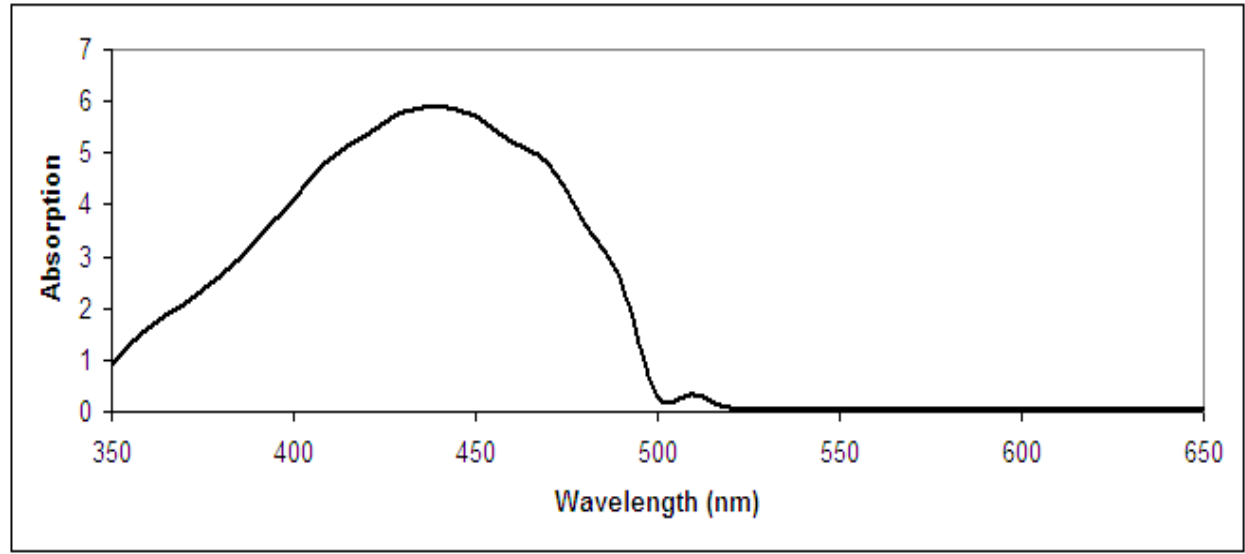

Fig. 1. UV/Visible spectrum of 2-anthracene triazole acrylate pigment. 
the average particle size of the microemulsions was increased by increasing the pigment content. Also, all of the prepared colored binders were found to be homogeneous, compatible and stable. Table 3 shows also that the prepared colored binders have good $\mathrm{Tg}$ which lies between 1.9 and 3.7; enabling them to use as binders for textile pigment printing. Tg values of the prepared colored binders were increased by increasing the pigment content. This may be attributed to the presence of bulky groups restricting the mobility of polymer chains [24].

Effect of monomers content ratio on the color strength and fastness properties of the prints

On the other hand the results of Table 4 represent the effect of monomers content ratio of the colored binder on the color strength and fastness properties of pigment printed areas. The color strength increased with increasing the pigment content in the colored binder from $13 \%$ to $17 \%$ but there is no significant increase in the color strength with the increasing of the pigment content from $17 \%$ to $20 \%$. All of the prints have very good fastness to light, washing, and perspiration. Also, all prints have good handle. From the data obtained it could be concluded that, the optimum monomer content ratio for colored binder preparation is $10 / 10 / 17[25,26]$.

Effect of the prepared binder concentration in the printing paste on properties of the pigment prints

To determine the optimum colored binder in the printing paste, five samples of cotton fabric were printed with different colored binder concentrations $18,20,22,24,26$ wt $\%$ of the printing paste. As illustrated by Figure 2, the color strength of the prints increased when the colored binder content was increased in the printing paste. Also, the suitable colored binder concentration in the printing paste is $24 \mathrm{wt} \%$ of the paste.

TABLE 3. Effect of monomers content ratio on the properties of micro emulsion polymer.

\begin{tabular}{cccc}
\hline AAc/BA/pigment wt\% & Average particle size (nm) & $\mathbf{T}_{\mathbf{g}}\left({ }^{\circ} \mathbf{C}\right)$ & Coagulation \\
\hline $10 / 10 / 13$ & 107 & 1.9 & No \\
$10 / 10 / 17$ & 148 & 2.3 & No \\
$10 / 10 / 20$ & 160 & 3.7 & No \\
\hline
\end{tabular}

TABLE 4. Effect of monomers content ratio on the color strength and fastness properties of the prints.

\begin{tabular}{|c|c|c|c|c|c|c|c|c|c|c|c|}
\hline \multirow{3}{*}{ AAc/BA/pigment wt $\%$} & \multirow{3}{*}{$\mathbf{K} / \mathbf{S}$} & \multirow{3}{*}{ Light } & \multirow{3}{*}{ Stiffness } & \multirow{2}{*}{\multicolumn{2}{|c|}{ Rubbing }} & \multirow{2}{*}{\multicolumn{2}{|c|}{ Washing }} & \multicolumn{4}{|c|}{ Perspiration } \\
\hline & & & & & & & & \multicolumn{2}{|c|}{ Acidic } & \multicolumn{2}{|c|}{ Alkaline } \\
\hline & & & & Dry & Wet & Alt & Stain & Alt & Stain & Alt & Stain \\
\hline $10 / 10 / 13$ & 4.7 & 8 & 1335 & $4-5$ & 4 & 5 & 5 & 5 & 5 & 5 & 5 \\
\hline $10 / 10 / 17$ & 5.3 & 8 & 1362 & 4 & $3-4$ & 5 & 5 & $4-5$ & 5 & 5 & 5 \\
\hline $10 / 10 / 20$ & 5.4 & $7-8$ & 1380 & 4 & $3-4$ & $4-5$ & $4-5$ & $4-5$ & $4-5$ & $4-5$ & $4-5$ \\
\hline
\end{tabular}

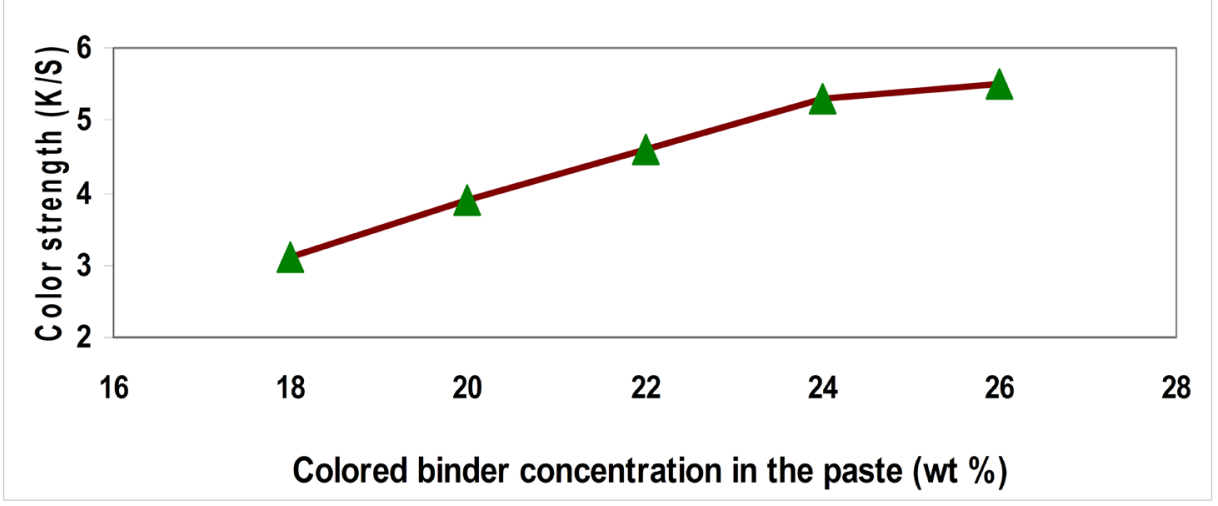

Fig. 2. Effect of colored binder concentration in the printing paste on the color strength of the prints. 
Color strength and fastness properties of the prints using the prepared binder on different types of fabrics

Table 5 represents the color strength and the fastness's properties of printed cotton, polyester or cotton/polyester blend fabrics using: The prepared colored binder and non-colored. From the data obtained, it is obvious that the use of colored binder enhanced the color strength and fastness properties of all fabrics types.

\section{Conclusion}

The present study involves the preparation of new pigment, 2-anthracene triazole acrylate, via click reaction. The prepared pigment was tested with different fabric types. Optimum pigment content in the printing paste and fastnesses properties of the prints were detected. The prepared pigment showed maximum UV/Visible absorption at $445 \mathrm{~nm}$.

The prepared pigment, butyl acrylate and acrylic acid monomers were copolymerized to produce colored binder (pigment particles became a part of binder chains). Cotton, polyester or cotton/polyester blend fabrics were printed using the prepared colored binder. The results were compared with those produced by non colored binder. It was found that the uses of colored binder improved the color strength and fastnesses properties of all fabrics types.

TABLE 5. Color strength and fastness properties of Pigment Print Pastes applied to cotton, polyester or cotton/polyester blend fabrics

\begin{tabular}{|c|c|c|c|c|c|c|c|c|c|c|c|}
\hline \multirow{3}{*}{$\begin{array}{c}\text { Fabric } \\
\text { type }\end{array}$} & \multirow{3}{*}{ Binder type } & \multirow{3}{*}{$\mathbf{K} / \mathbf{S}$} & \multirow{3}{*}{ Light } & \multirow{2}{*}{\multicolumn{2}{|c|}{ Rubbing }} & \multirow{2}{*}{\multicolumn{2}{|c|}{ Washing }} & \multicolumn{4}{|c|}{ Perspiration } \\
\hline & & & & & & & & \multicolumn{2}{|c|}{ Acidic } & \multicolumn{2}{|c|}{ Alkaline } \\
\hline & & & & Dry & Wet & Alt & Stain & Alt & Stain & Alt & Stain \\
\hline \multirow{2}{*}{ Cotton } & Non colored & 4.3 & 7 & $3-4$ & 3 & $4-5$ & $4-5$ & $4-5$ & $4-5$ & $4-5$ & $4-5$ \\
\hline & Colored binder & 5.3 & 8 & 4 & $3-4$ & 5 & 5 & $4-5$ & 5 & 5 & 5 \\
\hline \multirow{2}{*}{ Polyester } & Non colored & 4.0 & 7 & $3-4$ & 3 & $4-5$ & $4-5$ & $4-5$ & $4-5$ & $4-5$ & $4-5$ \\
\hline & Colored binder & 4.7 & 8 & 4 & $3-4$ & 5 & 5 & 5 & 5 & 5 & 5 \\
\hline $\begin{array}{l}\text { Cotton/ } \\
\text { polyester }\end{array}$ & Non colored & 4.1 & 7 & $3-4$ & 3 & $4-5$ & $4-5$ & $4-5$ & $4-5$ & $4-5$ & $4-5$ \\
\hline $\begin{array}{c}\text { blend } \\
65 / 35 \%\end{array}$ & Colored binder & 5.1 & 8 & 4 & $3-4$ & 5 & 5 & 5 & 5 & 5 & 5 \\
\hline
\end{tabular}

\section{References}

1- Rostovtsev, V.V., Green, L.G., Fokin, V.V. and Sharpless, K.B., A stepwise huisgen cycloaddition process: copper (I)-catalyzed regioselective "ligation" of azides and terminal alkynes. Angewandte Chemie, 114(14), 2708-2711 ( 2002).

2- van Steenis, D.J.V., David, O.R., van Strijdonck, G.P., van Maarseveen, J.H. and Reek, J.N., Click-chemistry as an efficient synthetic tool for the preparation of novel conjugated polymers. Chemical Communications, (34), 43334335, (2005).

3- Yoo, E.J., Ahlquist, M., Kim, S.H., Bae, I., Fokin, V.V., Sharpless, K.B. and Chang, S., Copper-Catalyzed Synthesis of N-Sulfonyl-1, 2, 3-triazoles: Controlling Selectivity. Angewandte Chemie, 119(10), 1760-1763 (2007).

4- Huisgen, R., 1, 3-dipolar cycloadditions. Past and future. Angewandte Chemie International Edition in English, 2(10), 565-598 (1963).
5- El- Nagawi, A. F. "Printing of Synthetic Fibers and Their Blends", $1^{\text {st }}$ ed. Alexandra, El-Maref Publisher (1984).

6- Thickett, S. C. and R. G. Gilbert, Emulsion polymerization: state of the art in kinetics and mechanisms. Polymer 48(24), 6965-699 (2007).

7- Chern, C. Emulsion polymerization mechanisms and kinetics. Progress in Polymer Science, 31(5), 443-486 (2006).

8- Oh, H. G., H. Shin, H. Jung, B. H. Lee and S. Choe, Control of molecular weight of polystyrene using the reverse iodine transfer polymerization (RITP)-Emulsion technique. Journal of Colloid and Interface Science, 353(2), 459-466 (2011).

9- Collins, J. D., H.; Gonzales, H.; Koniges, U. and Nordmeier, A, "Colloids and Emulsions", Washington, Spring (2007).

10- Gao, A. P. Mathematical modeling and computer simulator/database for emulsion polymerizations. Progress in Polymer Science, 27(3), 403-535

Egypt. J. Chem. 62, No. 2 (2019) 
(2002)

11- Kanehira, Tsutomu, and Koshi Saito. Stability of carthamin and safflor yellow B on silk powders under continuous irradiation of fluorescent or UV-C light. LWT-Food Science and Technology 34(2), 55-59 (2001).

12- An, K. C., and J. H. Kim. A study of the dyeability and physical properties of mordanted and finished fabrics dyed with natural dye of safflower. Journal of the Korean Society of Dyers and Finishers 13(1), 23-31 (2001).

13- Nam, Sung Woo, In Mo Chung, and In Hoi Kim. "Dyeing of Cotton Fabric with Natural Dye (I) -Safflower-. Textile Coloration and Finishing 7(2), 47-54 (1995).

14- Shin, Youn-Sook, Kyung-Hee Son, and Dong-Il Yoo. Dyeing properties and color of silk fabrics dyed with safflower yellow dye. Journal of the Korean Society of Clothing and Textiles 32(6), 928-934 (2008).

15- Legros, Camille. "Engineering of poly (2-oxazoline) $\mathrm{s}$ for a potential use in biomedical applications." (2015).

16- Elshemy N.S, Niazy W., Khalil E. M., Hamed M. S., Haggag K., Synthesis of Eco-friendly Binders from natural resources using microwave and their applications in textile Printing, Egyptian Journal of Chemistry 53(6), 903-921, December (2010).

17- Modification of Lyocell ${ }^{\circledR}$ and Modal ${ }^{\circledR}$ Fabrics and its Effect on the fabric Dyeability, Egyptian Journal of Chemistry, 53(6), 847-869, January (2010).

18- Judd, D.B. and Wyszecki, G., Physics and psychophysics of colorant layers, Color in Business, Science and Industry (1975).

19- AATCC. "Technical Manual Method 8", Method 8: 23 (1993).

20- AATCC. "Method 36". Technical Manual Method 36 (1993).

21- AATCC. Technical Manual 15. (1993).

22- AATCC. Color fastness to light: carbon - Arc lamb continuous light. Technical Manual Method 16A. Method 16A (1993).

23- ASTM standard test method for stiffness of fabric, Annual book of ASTM standards. method 1388 96, USA: 320 (2002).

24- Elshemy N.S., Hassabo A.G., Mahmoud Z.M., Haggag K., Novel Synthesis of Nano-emulsion Butyl Methacrylate/Acrilic Acid via Midroemulsion Polymerization and Ultrasonic waves, J. of Textile and Apparel, Technology and Management, 10 (1), 1-16 (2016).

25- Haggag, K., N. S. Elshemy, and W. Niazy. Recycling of Waste PET into Useful Alkyd Resin Synthesis by Microwave Irradiation and Applied in Textile Printing. Research Journal of Textile and Apparel 18(1), 80-88 (2014).

26- Allam, O.G., Elshemy, N.S., Hakeim, O.A. and Haggag, K., Synergistic Effect of Alkali Treatment and Microwave Irradiation on the Dyeing Properties of Polyester-Wool Blend Fabrics, International Journal of Science and Research, 4(9), 1697-1705 (2015).

(Received 4/6/2018; accepted 27/9/2018) 


\section{تحضير صبغات جديده غير مشبعة ب ـأنثراسين تريازول أكريليت لتحضير بيندرات ملونه بواسطة كيمياء النقر واستخدامها في طباعة المنسوجات

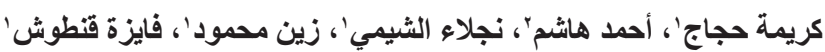

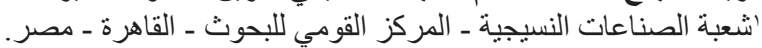

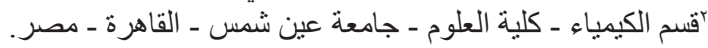

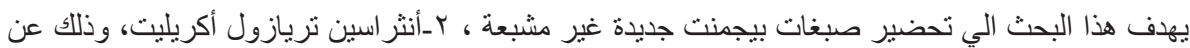

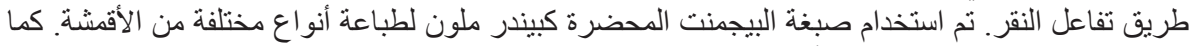

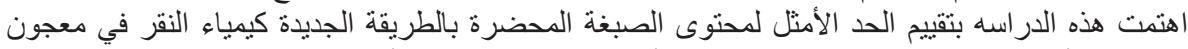

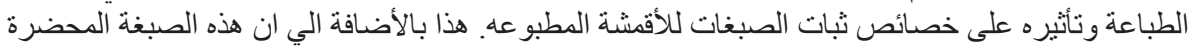

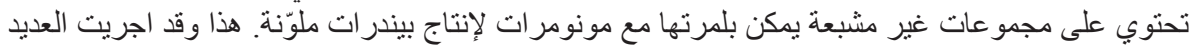

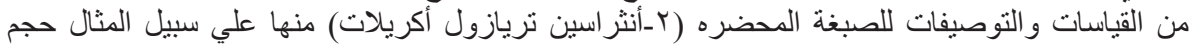

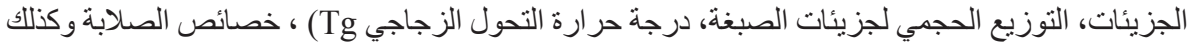

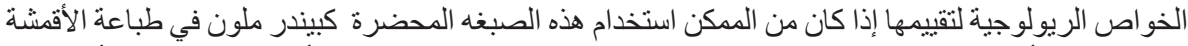

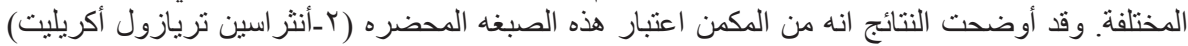

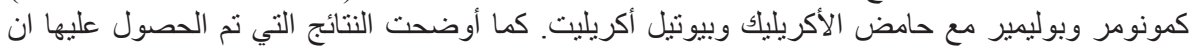

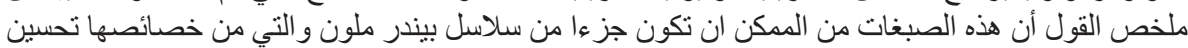

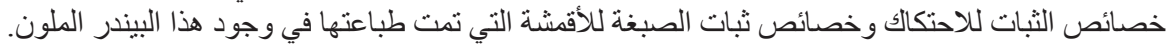

